\title{
A TRADUÇÃO-LOCALIZAÇÃO DE MARCAS
}

\author{
TRANSLATION-LOCALIZATION OF TRADEMARKS
}

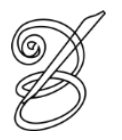 \\ Janaina Santos de Aquino ${ }^{1}$ \\ Bacharel em Letras-Tradução/UnB/Brasília/DF/Brasil \\ janainadeaquino@gmail.com \\ Cristiane Roscoe-Bessa ${ }^{2}$ \\ Professora Adjunta do Departamento de Línguas Estrangeiras e Tradução/UnB - Brasília/Brasil \\ crbessa@unb.br
}

\begin{abstract}
Resumo: A discussão sobre a tradução de marcas ganha atenção no mercado mundial, no qual empresas querem conquistar mercados novos em territórios estrangeiros. Constata-se que a marca é decisiva para a aceitação ou não de produtos por parte de futuros consumidores. Visto que mercados têm diferentes perfis, a obtenção de um efeito equivalente dessa marca tem demonstrado ser possível pela estratégia da localização desse item da embalagem. A localização da marca pode levar em consideração diferentes fatores, visto que grupos distintos em termos de cultura e língua têm demandas e necessidades distintas. Para tal, empresas visam a contratação de profissionais especializados que desenvolvam estudos sobre hábitos e costumes de uma determinada região. Diferentes fatores a serem observados na localização incluem: interesses individuais dos consumidores globais, o grau de tolerância de uma comunidade a línguas estrangeiras, cores da embalagem, a capacidade do consumidor para pronunciar os nomes de marcas estrangeiras, preferências culturais quanto aos tipos de nomes, se soam mais técnicos ou não, por exemplo, entre outros.
\end{abstract}

Palavras-chave: tradução; localização, novos mercados, marcas.

\begin{abstract}
The discussion about the translation of trademarks has gained ground in the world market, in which enterprises seek to sell their products in foreign territories. The trademark itself has shown to be of great importance for the acceptance of new products by future consumers. The same effect of a trademark in various communities has been achieved by localization since different markets have different profiles. Enterprises hire specialized professional that develop research on habits and customs of specific regions. The localization of a trademark takes different factors into consideration, since different groups in terms of culture and language have different demands and needs. Factors to be observed during localization include, among others, individual interests of global consumers, the degree of tolerance of a community toward foreign languages, colors of packages, the consumers ability to pronounce names of foreign marks, cultural preferences for certain types of names, as whether they sound technical or not.
\end{abstract}

Keywords: localization; new markets; trademarks; translation. 
No translation, no product

(Topping, 2000, p. 111)

tradução de rótulos de produtos industrializados, mais especificamente comestíveis
e cosméticos, que constitui o objeto maior de investigação neste artigo, revela-se
processo complexo, visto que suas partes requerem procedimentos diversos. Itens de rotulagem como "advertências" e "informações nutricionais", entre os demais, merecem igual atenção na discussão sobre tradução e localização e têm sido pesquisados pelas autoras. Entretanto, na medida em que a discussão sobre marcas cresce no cenário mundial, as considerações tecidas aqui se referem mais especificamente a esse item.

É por meio de uma marca, juntamente com os aspectos a ela associados, como a embalagem, que uma empresa chega até seus futuros consumidores. As grandes empresas têm buscado formas de adequarem suas marcas às comunidades externas ao seu contexto de origem para melhor aceitação de seus produtos. Para esse fim, a localização desse item da embalagem tem demonstrado ser imprescindível.

44 Assim, para vender uma marca em diferentes países, o que implica sua traduçãolocalização para diferentes línguas e culturas, algumas grandes corporações precisam amiúde adaptar o nome das suas marcas. A necessidade de localização decorre do fato de que nem sempre o nome de uma marca causa o mesmo efeito no país de destino, e pode, às vezes, ter até mesmo efeito adverso ao do original.

A tradução "é mais do que apenas uma transferência linguística cuidadosa: é uma ação proposital projetada para alcançar o resultado mais efetivo em um grupo-alvo"3 (SANGZHANG, 2008, p. 2). Tal constatação revela que a localização deve considerar estratégias de marketing que melhor contribuam para uma comunicação efetiva com consumidores e essas devem, portanto, ser observadas pelo tradutor-localizador.

Ressalte-se que, conforme explica Maillot, "a decisão definitiva sobre a escolha de um termo que pode suscitar contestação pertence, não ao autor da tradução, mas àquele que se reserva o direito de explorar o produto em questão" (1975, p. 89). A análise de eventuais desacertos na tradução de marcas, no âmbito da localização, pode evidenciar o uso de estratégias inadequadas e a ausência de conhecimento sobre a cultura da comunidade meta. 


\section{Marcando território}

Para Fernanda Borges, a marca é mais do que um cartão de visitas de uma empresa, que transmite, "através das cores e do design, algo sobre a personalidade e benefícios do produto" (2006, sp.). Além de ajudar o consumidor a distinguir um produto de outro, a marca também constitui um veículo para a venda do produto e, caso seja mal planejada ou explorada, pode ser associada a um baixo padrão de qualidade, o que pode acarretar pouca aceitação ou pouca atração por parte do consumidor. Além disso, a marca também tem importância especial na indústria alimentar, uma vez que pode ter consequências diretas para a saúde do consumidor (AZEVEDO, 2007).

Por outro lado, uma pesquisa encomendada pelo FIESP ao IBOPE ${ }^{4}$, em 2010, sobre o perfil de consumo dos brasileiros sugeriu que a marca tem perdido força como fator mais importante na decisão de compra de alimentos no país, seguindo uma tendência mundial. Entretanto, isso não significa que a sua presença nos produtos seja dispensável, apenas que os consumidores brasileiros têm se mostrado cada vez mais preocupados com outros atributos do produto, como teor nutritivo e qualidade $(2010, \mathrm{sp}$.$) , aspectos esses que devem ser traduzidos$ em sua íntegra.

Além de ser associada à qualidade, ou fatores mais recentes como sustentabilidade, uma marca também é constantemente adaptada para grupos alvo específicos, o que motiva, por exemplo, a criação de linhas de produtos.

De acordo com Rafael Mauricio Menshhein, “as organizações tendem a expandir suas linhas de produto por diversos motivos, trazendo uma fatia maior de consumidores, permitindo reduzir custos, fortalecer o portfólio, fixar a Marca [sic] na mente do consumidor etc.” (2007, sp.). Para Alex Ribeiro, consultor em marketing digital, "[a] importância do nome de um produto ou linha de produtos é tão relevante quanto o nome e marca da empresa, pois cria vínculo com os clientes que passam a identificar o produto pelo nome que ele possui, pela cor, embalagem" (2007, sp.).

Esses autores concordam, portanto, que uma marca é importante não apenas para atrair a atenção do consumidor, mas para mantê-lo como um cliente fiel. Além disso, conforme relata Azevedo, uma "[u]ma Marca [sic] associada a um produto de qualidade não pode correr o risco de identificar um produto inferior que possa pôr em causa a própria saúde do consumidor" (2007, sp.). Neste sentido, as empresas devem estar atentas aos prejuízos que a má elaboração de uma marca pode acarretar, em especial quando desejam expandir as vendas para mercados externos (cf. item 3.3). 
Nesse caso, a preocupação das empresas vai além da questão de lançar uma nova linha a cada estação ou de se especializar em um grupo específico. Trata-se de adaptar-se a grupos culturais e linguísticos diversos, cujas necessidades e demandas variam de um país a outro ou, ainda, de uma região a outra dentro do mesmo país. Consoante o conceito de localização, estes mercados potenciais são chamados de locales, que significa tanto uma variação linguística quanto um conjunto de preferências culturais (PYM, 2005, p. 2).

Por isso, as empresas têm investido na contratação de profissionais especializados para realizar pesquisas de mercado e de opinião, além de estudos sobre os hábitos e costumes de uma determinada região a fim de chegar a uma tradução mais adequada, no processo de localização da marca do produto.

\section{Tradução de marcas: adaptar para localizar?}

Em um manual sobre a localização de marcas, a empresa internacional de consultoria, Pleon, sediada na Europa, declara que "assim como as celebridades precisam de fãs, as marcas também precisam de grupos-alvo" ". Segundo a empresa, a localização de marcas é "um fator crucial para o sucesso" e, por isso, encoraja os clientes a aprenderem sobre os grupos-alvo dos seus produtos para descobrir de que forma eles percebem uma "marca local" e a empresa possa, assim, transmitir sua mensagem falando a língua de seus futuros clientes.

Corroborando essa linha de pensamento, um estudo realizado por Zia Daniell Wigder et. al. (2009), sobre tradução e localização de sites de varejo, revelou que $95 \%$ dos consumidores chineses on-line afirmaram se sentir mais confortáveis em sítios online que apresentavam informações traduzidas em seu idioma.

Em contrapartida, apenas $1 \%$ dos varejistas norte-americanos online consultados ofereciam sítios na Internet planejados especificamente para o mercado chinês. Ainda nessa mesma linha, de acordo com um estudo intitulado "Can't Read, Won't Buy: Why Language Matters on Global Websites" (DEPALMA et. al., 2006), que contemplou o Brasil, 56,2\% dos consumidores entrevistados afirmaram que a possibilidade de obter informações na sua própria língua é mais importante do que o preço do produto (2006, p. 7):

\footnotetext{
A suposição de que compradores em potencial "provavelmente falam inglês" resulta em um processo de localização inadequado, o que contraria a sensação de que as pessoas não pagarão por produtos que não conseguem compreender ou que não têm nenhuma apelação para elas ${ }^{6}$. (DEPALMA et. al., 2006, p. 5).
} 
O referido estudo constatou, ainda, que uma marca pode até triunfar sobre o idioma de um povo, mas o idioma triunfará sobre o preço do produto. Em outras palavras, os resultados do estudo mostraram que uma parcela considerável (61\%) dos consumidores entrevistados declarou que preferiria um produto de marca mundial de boa reputação, mas sem informações em seu idioma nativo, a outro produto, de marca menos conhecida, com informações na língua materna. Por outro lado, o estudo observa que "a supremacia da marca constitui definitivamente uma má notícia para qualquer empresa de marca menos conhecida ao tentar entrar no mercado internacional"7 (2006, p. 27). Conclui-se que, sem o poder de um nome mundialmente reconhecido, as empresas que estão apenas começando sofrem uma maior resistência da comunidade meta na compra do produto. Neste sentido, é recomendável para a empresa contratar os serviços de profissionais especializados para evitar quaisquer fatores que dificultem ou prejudiquem a introdução e comercialização da marca em solo estrangeiro.

\section{Aspectos a serem considerados}

Em relação à linguagem, tais fatores podem incluir impactos causados pela tradução de nomes de marcas. Por isso, a capacidade do consumidor para pronunciar os nomes de marcas estrangeiras é outro fator decisivo a ser considerado. De acordo com Bik-Yan (2007), em um estudo sobre a tradução de nomes de marcas na China, é o idioma que regula o que é possível e o que não é [em uma tradução]:

\footnotetext{
Algumas características são encontradas em todas as línguas do mundo, enquanto outras não são encontradas em lugar nenhum. Para atender o requisito de ser "pronunciável em todas as línguas", o designer da marca deve conhecer os fonemas comuns na maioria dos idiomas. As marcas atuais devem passar por melhorias na tradução para evitar a pronúncia inadequada das marcas $^{8}$. (2007, p. 33, grifo das autoras)
}

Outro fator pode ser a tolerância de um determinado mercado consumidor a marcas em língua estrangeira. Por exemplo, a marca de loja de departamentos canadense "Eaton' $s$ " teve que reduzir seu nome para a "Eaton" (sem apóstrofo) em Quebec, porque "Eaton's" soava "muito inglês". Neste sentido, ignorar a tendência mundial de transformar o local em global e depois em local - ou seja, para um novo locale - pode diminuir o interesse dos consumidores internacionais pelos produtos de empresas que resistem ao serviço de tradução e localização, pois alguns estudos realizados têm demonstrado que os consumidores preferem cada vez mais ler em seu próprio idioma. 
A este respeito, Chris Boorman, gerente de marketing na $S D L$, relata que os Estados Unidos têm perdido espaço no mercado mundial devido à sua pouca habilidade em lidar com outras línguas. E quando o faz, é de forma antiquada, arrogante e até colonial. Consequentemente, no ranking das 100 principais marcas globais, coordenado pela Interbrand, uma consultoria de marketing, 51 nomes norte-americanos foram citados em 2010, contra 64 em 2003. Essa queda, embora pouco significativa, revela que a falta de cuidado com os interesses individuais dos consumidores globais pode resultar na constante perda de mercado para empresas que tem investido nesses serviços.

Outros fatores mais subjetivos incluem as cores. De acordo com Derrick Daye, consultor de publicidade e comercialização de produtos, "além de aumentar a visibilidade na prateleira, o uso apropriado de cores pode aumentar o reconhecimento da marca em até $80 \%$, ao mesmo tempo em que também serve como um importante identificador da marca". (2011, sp.). Por exemplo, além da tipografia exclusiva, o vermelho da Coca-cola pode ser encontrado no mundo inteiro, mesmo que o nome "Coca-Cola" não esteja explicitamente escrito (KAPFERER, 2008, p. 473). Em contrapartida, uma determinada paleta de cores também 48 pode repelir o desejo de compra do consumidor devido aos significados culturais das cores usadas naquela região. O estudo “Global Market Bias: Part 1- Color” sobre cores e mercados mundiais impulsionados pelas marcas, constatou que o amarelo é mundialmente identificado como cor alegre, mas na China $18 \%$ dos consumidores pensam diferente. Corroborando essa linha de pensamento, Susan Gunelius, especialista em marcas e publicidade ${ }^{9}$, diz que, ao tratar-se de uma marca mundial, é essencial que a empresa aprenda sobre o significado das cores em outras regiões do mundo antes de escolher a paleta do seu logotipo, materiais de publicidade etc. que serão comercializados em determinados mercados. O vermelho pode ser sinônimo de boa sorte na China e em partes da África, mas sinal de perigo ou aviso na Austrália e Nova Zelândia. Por esta razão, antes de exportar para essas regiões, a empresa deve certificar-se que transmitirá a mensagem e a imagem da sua marca sem causar impactos negativos na comunidade meta.

As possíveis variações de nomes de marcas em diferentes países também devem ser consideradas nas estratégias de localização. É interessante observar que, ao viajar para outro país, o visitante poderá encontrar além de ruas, rostos, línguas e costumes diferentes, produtos com nomes diversos daqueles encontrados no seu país. Participantes de inúmeros fóruns da Internet relatam a experiência de viajar para outro continente e constatar, com surpresa, produtos presentes em seu país com nome ligeira ou totalmente distinto. Não fossem 
as mesmas cores e os formatos da embalagem e do logotipo, alguns participantes afirmam que sequer seriam capazes de dizer que se tratava do mesmo produto, devido à adaptação do nome. Por exemplo, a marca de desodorante "Sure", produzida pela Unilever, é comercializada como "Rexona" no Brasil, e como "Degree" nos Estados Unidos e Canadá. A ortografia "Rexona" muda ligeiramente no Japão e na Coréia, onde é conhecida como “Rexena". Em todos esses países, o logotipo da empresa, acompanhado do símbolo $(\checkmark)$, é o mesmo. Uma das razões para esta mudança é que, assim como as cores, nomes podem ter significados indesejáveis em línguas estrangeiras, o que requer a criação de uma nova marca. Além disso, é possível que exista ou tenha existido uma marca concorrente com nome similar. Há casos, ainda, em que o mesmo nome refere-se a produtos diferentes, cuja marca já existia na região.

Às vezes, trata-se apenas de preferências culturais quanto aos tipos de nomes, também. Aparentemente, os europeus preferem nomes que soam técnicos para artigos de higiene pessoal, enquanto os americanos parecem considerar nomes técnicos "fora de contexto" para esse tipo de produto (como a marca de papel higiênico "Andrex" no Reino Unido e "Cottonelle" nos Estados Unidos). Na Europa, em geral, os nomes dos produtos de higiene pessoal são comercializadas em lugares específicos, ou seja, é necessário ir a uma farmácia para comprar aspirinas, enquanto, nos Estados Unidos, é possível comprá-las em supermercado. Por isso, os nomes de produtos desse tipo ainda tendem a soar clínicos na Europa, enquanto nos Estados Unidos continuam associados à vida cotidiana. Assim, observase que diferentes fatores, entre eles linguísticos e culturais, relacionados à marca interferem e influenciam na escolha do consumidor por determinado produto.

\section{Tradução de nomes de marcas estrangeiras: problemas e soluções}

Em um artigo sobre a importância da marca, Monti (2010) aponta alguns fatores que devem ser considerados para atingir o efeito desejado pela empresa, incluindo o de ser lembrado pelo cliente. Assim, uma marca "[n]ão deve ter conotações pejorativas em outros idiomas ou na maneira dos habitantes se expressarem na localidade onde será instalada a loja” (2010, sp.).

Exemplos desse tipo podem ser encontrados em inúmeros artigos na internet. Observou-se que alguns desses artigos se limitam a enumerar os erros de tradução para evidenciar as situações cômicas e irônicas provocadas. Outros artigos, contudo, preocupam-se com esse fato, a ponto de usá-lo como exemplo e como lição, com o objetivo de alertar sobre 
os prejuízos causados por tais erros e sugerir técnicas de tradução e localização que eliminem os referidos inconvenientes ou evite-os no futuro.

Entre os nomes de marcas ou campanhas publicitárias que, na tentativa ou falta de estratégia de localização cometeram gafes, conforme mostra o artigo intitulado "How not to sell abroad" ("Como não vender no exterior"), do sítio online Small Business, incluem a marca de camas "Gutvik". Quando comercializada na Alemanha, a pronúncia do nome da marca soava muito próximo a "boa transa".

Já o chocolate "La Dulcería Thalía", da produtora de chocolates Hershey's, cujo recheio de creme de caramelo que dá nome ao produto é chamado "cajeta" (Figura 32) não encontrou problemas nos mercados mexicanos, mas em outros países hispanofalantes, como Argentina e Uruguai, o nome do recheio podia ser interpretado como uma gíria vulgar usada para o órgão genital feminino.

No Brasil, em meados dos anos 1970, a produtora de automóveis americana Ford desistiu de fabricar e vender o modelo "Ford Pinto" no país por dois motivos, um financeiro e outro, obviamente, linguístico. Em primeiro lugar, os custos para adaptar as linhas de 50 montagem de produção seriam aparentemente exorbitantes. Em segundo lugar, a empresa teria que mudar o nome do modelo em território brasileiro, visto que é uma gíria popular para aludir ao órgão genital masculino. Esses exemplos evidenciam a importância da adoção de estratégias cuidadosas, com o objetivo de impedir a ocorrência de inadequações de tradução.

O famoso nome da Coca-Cola, por exemplo, quando introduzida na China, foi traduzida como "Ke-kou-ke-la" (Figura 33), a fim de manter os aspectos estéticos e fonéticos. Infelizmente, a empresa descobriu, somente após imprimir milhares de cartazes comerciais para promover o produto, que o termo escolhido significava "morder o girino de cera" ou "égua recheada com cera", dependendo do dialeto. Após pesquisar 40.000 ideogramas, a empresa encontrou um equivalente fonético, "Ko-Kou-Ko-Le", que pode ser livremente traduzido como "felicidade na boca".

Desta forma, a tradução, neste caso, envolve mais do que uma equivalência em termos linguísticos, que mantenha os aspectos fonéticos. No que diz respeito ao mandarim, estudos como o de F.C. Hong et. al. (2002) têm revelado que, nas traduções de línguas baseadas em alfabeto para línguas de caracteres como o mandarim, são utilizados basicamente dois métodos genéricos de tradução de marca: (1) tradução direta para o sentido do nome da marca ou (2) tradução fonética para a pronúncia do nome da marca. Bik-Yan, por sua vez, em um estudo sobre tradução de marcas, explica que a língua chinesa tem um grande número de 
homônimos, isto é, a pronúncia chinesa de certas palavras corresponde a pelo menos dez caracteres distintos, com significados igualmente distintos, dependendo de como a palavra é pronunciada (2007, p. 9). Verifica-se, assim, que o tradutor do nome da "Coca-Cola" para o mandarim adotou a segunda estratégia, que se mostrou ineficaz ao ignorar essas características peculiares e cruciais da língua.

Em suma, observa-se que os fatores relacionados à marca de um produto nacionalmente conhecido estão profundamente enraizados na mente dos clientes do seu país de origem. No entanto, ao chegar a um mercado estrangeiro, a marca original nem sempre é conhecida, de forma que são necessárias algumas estratégias para conquistar a mesma popularidade do país de origem. Sem dúvida, a tradução-localização deve estar entre essas estratégias, pois a marca traduzida é tão importante quanto o seu nome original. Portanto, as ideias originalmente presentes em uma determinada marca devem ser passadas adequadamente no processo de tradução-localização, visto que a perda desses elementos pode significar também a perda de identidade da marca.

\section{Conclusões}

Ao expandir seu alcance no mercado mundial, grandes e pequenas empresas precisam procurar estratégias de como melhor localizar sua marca a fim de consegui melhor aceitação de seus produtos em comunidades estrangeiras, principalmente onde a população tem aversão a empresas estrangeiras por motivos patrióticos e culturais. Se, em alguns casos, a tradução pode não ser a opção mais adequada; a título de exemplo, uma busca na Internet pelos logotipos de algumas marcas mostrou que os aspectos gerais da embalagem dessas marcas permaneceram muito parecidos em quase todos os países onde foram localizadas, com pequenas alterações em um país ou outro. Em outros casos, como demonstrado, a falha em traduzir, o nome das camas "Gutvik" e do recheio "cajeta" provaram exatamente que a tradução-localização é, ainda, a melhor estratégia a ser adotada.

Tradutores não podem deter pouco conhecimento sobre a língua ou comunidade meta e as traduções devem ser feitas por profissionais da área, de preferência especialistas em localização. A localização desse item da embalagem se mostrou amiúde uma necessidade devido ao fato de consumidores terem reações e impressões adversas em seus diferentes ambientes.

Se a marca tem importância fundamental para a comercialização de um produto, o tradutor deve compreender e discutir os fatores envolvidos na tradução-localização de marcas, 
cujo respaldo encontra-se também em estudos realizados na área de publicidade e propaganda. No cenário internacional, empresas permanecem em busca de orientações sobre a melhor maneira de adequar seus produtos a um mercado externo.

\section{REFERÊNCIAS BIBLIOGRÁFICAS}

AZEVEDO, Laura. A Importância da Marca na indústria alimentar. Disponível em: <http://www.hipersuper.pt/2007/09/07/a-importncia-da-marca-na-indstria-alimentar/>.

Acessado em 22 de abril de 2011.

BIK-YAN, Chan. Brand Naming - A study on brand name translation in China: U.S. brands translated into Chinese and Chinese brands translated into English. Disponível em: 〈http://libproject.hkbu.edu.hk/trsimage/hp/04013301.pdf >. Acessado em junho de 2011.

BOORMAN, Chris. In: Marketers take a fresh look at the language barrier. Disponível em: $\quad<h t t p: / / w w w . n y t i m e s . c o m / 2007 / 07 / 22 /$ business/worldbusiness/22iht$\operatorname{ad} 23.1 .6765550 . \mathrm{html}>$. Acessado em 27 de maio de 2011.

BORGES, Fernanda. A importância da marca. Disponível em: <http://pt.shvoong.com/humanities/371779-importância-da-marca/\#ixzz1KHZx5JBw>.

$52 \quad$ Acessado em 22 de abril de 2011.

BtB. What is localization? - Translation Bureau. Disponível em: $<$ http://www.btb.gc.ca/btb.php?lang=eng\&cont=213>. Acessado em 04 de junho de 2011.

DAYE, Derrick. Brand Packaging: Solving The Mystery Of Shelf Impact. Disponível em: http://www.brandingstrategyinsider.com/branding_and_colors/. Acessado em 27 de maio de 2011.

DePALMA et. al. Can't Read, Won't Buy: Why Language Matters on Global Websites. Disponível em:

http://www.forrester.com/rb/Research/translation_and_localization_of_retail_web_sites/q/id/5 4629/t/2>. Acessado em 23 de maio de 2011.

HONG, F. C. PECOTICH, Anthony. SHULTZ II, Clifford J. Brand name translation: Language constraints, product attributes, and consumer perceptions in East and Southeast Asia. Disponível em: < http://www.jstor.org/pss/25048888>. Acessado em 3 de junho de 2011.

KAPFERER, Jean-Noël. The new strategic brand management: creating and sustaining brand equity long term. Disponível em: http://books.google.com/books?id=8PoItiB7bicC\&pg=PA494\&lpg=PA494\&dq=brands+acco rding+to+countries+colours\&source=bl\&ots=ewUe4zsJYC\&sig=k32ZqzGPf6IQ_KqEV4jpA O2GjoY\&hl=en\&ei=fvzfTZaXG4WutweYhJ2OCg\&sa=X\&oi=book_result\&ct=result\&resnu $\mathrm{m}=4 \& v e d=0 C D A Q 6 A E w A w \# v=$ snippet $\& \mathrm{q}=$ colour $\& \mathrm{f}=$ false. Acessado em: 27 de maio de 2011. 
MAILlOT, Jean. A tradução científica e técnica. Trad. Paulo Rónai. São Paulo: McgrawHill do Brasil; Brasília: Ed. da Universidade, 1975.

Marca deve perder importância na compra de alimentos mostra pesquisa. Disponível em: <http://oglobo.globo.com/economia/mat/2010/05/18/marca-deve-perder-importancia-nacompra-de-alimentos-mostra-pesquisa-916614647.asp>. Acessado em 22 de abril de 2011.

MENSHEIN, Rafael Mauricio. Disponível em: <http://www.portaldomarketing.com.br/Artigos1/Linhas_de_produto_em_Marketing.htm>. Acessado em 23 de abril de 2011.

MONTI, Roberto. A A importância da marca. http://www.acessa.com/negocios/arquivo/dicas/2001/10/11-Monti/. Acessado em 23 de abril de 2011.

Produtos de higiene e beleza com nome em inglês perde mercado. Disponível em: $<$ http://www.empreendedor.com.br/noticias/produtos-de-higiene-e-beleza-com-nome-eming1\%C3\%AAs-perde-mercado>. Acessado em 23 de abril de 2011.

PYM, Anthony. Localization: On its nature, virtues and dangers. 2005. Disponível em: $\langle$ http://usuaris.tinet.cat/apym/on-line/translation/loclinguistics.pdf $>$. Acessado em maio-junho de 2011.

SANG, Jian. ZHANG, Grace. Communication across languages and cultures - A perspective of brand name translation from English to Chinese. Disponível em: <benjamins.com/jbp/series/JAPC/18-2/art/07san.pdf>. Acessado em junho de 2011.

WIGDER, Zia Daniell. EVANS, Patti Freeman. CAMUS, Lauriane. MCGOWAN, Brendan. Translation and Localization of Retail Web Sites. Disponível em: < http://www.forrester.com/rb/Research/translation_and_localization_of_retail_web_sites/q/id/5 4629/t/2>. Acessado em 23 de maio de 2011.

\footnotetext{
${ }^{1}$ Currículo Lattes. Janaina Santos de Aquino. Disponível em: http://lattes.cnpq.br/6742222105266018.

${ }^{2}$ Currículo Lattes. Cristiane Roscoe Bessa. Disponível em: http://lattes.cnpq.br/0039122901216440.

3 "[translation] is more than just a careful linguistic transfer: it is a purposeful action designed to achieve the most effective result in a target group."

${ }^{4}$ Para saber mais: Marca deve perder importância na compra de alimentos, mostra pesquisa. Disponível em: http://oglobo.globo.com/economia/mat/2010/05/18/marca-deve-perder-importancia-na-compra-de-alimentosmostra-pesquisa-916614647.asp.. Acesso: 22 de abril de 2011.

5 "Just as stars need fans, so do brands need target groups."

6 "The assumption that potential buyers "probably speak English" drives inadequate localization, warring against the gut feeling that people are unlikely to buy products they cannot understand or that do not appeal to them."

7 "[However,] the preeminence of brand constitutes decidedly bad news for any company with a lesser known mark as it tries to market to international audiences."
} 
8 "Some characteristics are found in all the world's languages while others are not found in any. In order to fulfill the requirement to be "pronounceable in all languages", the brand name designer must know the common phonemes for most languages.

9 GUNELIUS, Susan. Color Meanings Around the World. Disponível em: http://www.everyjoe.com/2007/09/23/work/color-meanings-around-the-world/. Acesso: 27 de maio de 2011

54 